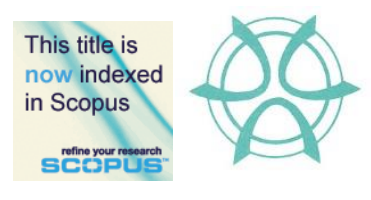

PLANNING MALAYSIA:

Journal of the Malaysian Institute of Planners

VOLUME 17 ISSUE 2 (2019), Page 168 - 178

\title{
SOURCE WATER PROTECTION FROM PHARMACEUTICAL CONTAMINANTS: ASSESSMENT OF ENVIRONMENTAL QUALITY ACT 1974 AND ITS REGULATIONS
}

\author{
Adillah Othman ${ }^{1} \&$ Mariani Ariffin ${ }^{2}$ \\ ${ }^{1,2}$ Faculty of Environmental Studies \\ UNIVERSITI PUTRA MALAYSIA
}

\begin{abstract}
Pharmaceutical contaminants have become a global "emerging pollutant". Many countries developed various policies and technologies to deal with the problem. In Malaysia, there is no serious attention given to this problem in the Environmental Quality Act 1974 (EQA) and other regulations (Malaysian legislation). Therefore, pharmaceutical contaminants still enter the environment and affect human health through water consumption and water usage. In response to this problem, this study aims to analyse Malaysian legislation and to identify potential protection provided to protect source water from pharmaceutical contaminants. This study employed a qualitative approach. A systematic search was carried out on existing pharmaceutical-related Malaysian legislation. Later, content analysis was conducted to discover patterns and ideas within the existing legislation. This would determine the provisions that could assist the protection of source water from pharmaceutical contaminants. The findings of this study demonstrate only few provisions addressed the problem of pharmaceutical contaminants and thus, this type of contaminant continues to harm the environment. It is hoped that the result of this study could enhance Malaysian legislation pertaining to the problem and minimise the risk of pharmaceutical contaminant in drinking water.
\end{abstract}

Keywords: drug disposal; emerging contaminant; Environmental Quality Act; Malaysia; pharmaceutical residues; source water; waste management; water pollution 
PLANNING MALAYSIA

Journal of the Malaysia Institute of Planners (2019)

\section{INTRODUCTION}

Pharmaceutical contaminants caused by the production residue, improper disposal of expired and unused medication, accidental spills during manufacturing and distributing, as well as from the raw and treated effluent discharged from housing areas and hospitals, which are later brought into the rivers (Al-Odaini, Zakaria, Yaziz, Surif, \& Abdulghani, 2011; Boleda, Galceran, $\&$ Ventura, 2011; Kookana et al., 2014). Pharmaceuticals which are neither volatile nor biodegradable escaping sedimentation and biological treatment in sewerage treatment plan (STP) and their metabolites enter the water bodies (AlOdaini et al., 2011; Boleda et al., 2011; Jelic et al., 2011). There were reports showing pharmaceutical contaminants having toxic impact onto environment and human especially through water consumption and water usage (Alshakka, Ibrahim, Hassali, Palaian, \& Aljadhey, 2016).

Pharmaceutical contaminants also found in Malaysian source water. Source water refers to "any river, river basin, ground water, and water body" as defined by Selangor Water Management Authority Enactment 1999. However, there is no explicit regulation that governs the issue of pharmaceutical-safe source water as pharmaceutical waste is considered as a non-priority pollutant (AlOdaini et al., 2011; Al-Odaini, Zakaria, Yaziz, \& Surif, 2016). Malaysian legislation only deal with the problem of pollution in general and the legislation themselves are scattered and piecemeal. Furthermore, the extent of their enforcement is disputable since source water management in Malaysia is also regulated under the state legislation.

This study focuses on source water protection from pharmaceutical contaminants in Malaysia by evaluating Malaysian legislative framework to mitigate the risk of pharmaceutical contaminants from entering source water. This include management, monitoring, and surveillance to ensure continuous protection of source water as they could provide information for identifying threats and hazards, also targeting source water protection and management strategies towards issue concern (Canadian Council of Ministers of the Environment, 2004; Plummer, Velaniskis, de Grosbois, Kreutzwiser, \& Rob, 2010; The Council of the European Union, 1998; World Health Organization, 2004, 2011).

\section{MATERIALS AND METHODS}

This study is qualitative in nature. Secondary data were systematically selected, consisting of legal documents in Malaysia such as EQA and its regulations related to the problem of pharmaceutical contaminants. These sets of document have been searched through various databases such as Google Scholar, Mendeley, and from the official website of relevant government agencies including Department of Environment, Ministry of Health, and Ministry of Ministry of Energy, Green Technology, and Water. Specific keywords were used such as "pharmaceutical 
Adillah Othman \& Mariani Ariffin

Source Water Protection from Pharmaceutical Contaminants: Assessment of Environmental Quality Act 1974 and Its Regulations

waste", "pharmaceutical pollutant", "clinical waste", "medical waste", "waste management law in Malaysia", "pharmaceutical law in Malaysia", "pharmaceutical waste policy", and "pharmaceutical legislation". Only relevant legal documents related to source water protection from contaminants were scrutinised and finalised. Selected legal documents have been sent to experts for validation purposes to ensure their comprehensiveness and could cater the problem of pharmaceutical contaminants in source water. Data collected were analysed using content analysis approach. The raw data was coded and categorised according to themes. Nvivo10 software was utilised to carry out the content analysis and to ensure the collected data was systematically managed. This was also vital for the development of 'cognitive mapping' and framework matrices for the data.

\section{RESULTS}

Coding was done by examining selected Malaysian legislation. After indicators were identified, categories and sub-categories were inductively generated and given specific description to ensure the analysed legislation came within the ambit of the definition. The indicators, categories, and sub-categories and discussed below.

\section{Provision Related to Source Water Management and Protection from Hazardous Substance}

\section{Control of Effluent Discharge}

Section 25 and 27 of EQA made the restriction on pollution of inland waters by discharging any environmental hazardous substance (EHS), pollutant or waste unless licensed by the authority. Further, in Section 34B prohibits scheduled wastes from entering Malaysian waters. Section 2 of the same Act defines 'scheduled wastes' as any waste prescribed by the minister in the regulations as scheduled wastes. The 'regulations' referred in Section 2 of EQA is Environmental Quality (Scheduled Wastes) Regulations 2005 (EQSWR). EQSWR further defines 'scheduled wastes' as any waste falling within the categories of waste listed in the First Schedule. SW 4 of the First Schedule lists wastes from discarded drugs, clinical, pharmaceutical preparation, production products, and residues from treatment or recovery of scheduled wastes to be part of 'scheduled wastes' category.

Furthermore, Regulations 4, 5, 9, and 10 of EQSWR details out that scheduled waste should be disposed and treated as according to regulations' requirement, such as labelling for identification and warning purposes as well as procedure for storage of schedule waste to prevent spillage or leakage into the environment. The activities should be conducted at 'prescribed premises' whereby 'prescribed premises' refers to premises prescribed in Order 3 of 
PLANNING MALAYSIA

Journal of the Malaysia Institute of Planners (2019)

Environmental Quality (Prescribed Premises) (Scheduled Wastes Treatment and Disposal Facilities) Order 1989 (EQPSO), which includes off-site storage facilities, off-site treatment facilities, off-site recovery facilities, scheduled waste incinerators, land treatment facilities, and secure landfills.

Regulations 11, 12, and 13 of Environmental Quality (Industrial Effluent) Regulation 2009 (EQIER) specified certain parameter under Fifth Schedule for the discharge of industrial effluent or mixed effluent. There are two standards applicable for each parameter, namely Standard A for the discharge into catchment listed under Sixth Schedule, and Standard B for the discharge into any other inland water or Malaysian water or other than what has been listed under Sixth Schedule.

\section{Risk Mitigation from Accidental Discharge}

There are regulations that deal with the risk prevention of the source water threat and pollution including on the risk of spillage or accidental discharge of the contaminant into soil or inland waters. For instance, Regulation 20 of EQIER and Regulation 14 of EQSWR mentioned that the person who caused any spillage or accidental discharge of scheduled waste (Reg. 14), industrial, and mixed effluent (Reg. 20) which either directly or indirectly gains or may gain access into soil or inland waters, shall immediately notify the Director-General of Environmental Quality about the occurrence. On top of that, the person shall perform any necessary action to cleanse the spill or discharge and must also determine the impact of such spillage or accidental discharge towards the environment.

\section{Administrative Platform}

Administrative platform is classified into two, which are general administration practices and monetary administration that is strictly covers the environmental fund.

General administration practice includes 'environmental audit' as in Section 33A of EQA, which plays an important role as it could be considered as the main Section to ensure the requirements set out under legislation were complied. Several Environmental Quality Regulations such as EQIER, EQSWR, and Environmental Quality (Sewage) Regulations 2009 ('EQSR') have laid down the acceptable condition of the contaminant to be discharged into source water and the 'receiving place' which the contaminant or waste should go. Without an environmental audit, the authority will bear more burdens in ensuring compliance of the regulations.

In term of monetary administration, Section 36B, 36D, and 36E of EQA have specified on the establishment of 'environmental fund' for the purpose of preserving the environment and mitigating the pollution including preventing the occurrence of discharge and dumping of EHS and waste and encouraging 
Adillah Othman \& Mariani Ariffin

Source Water Protection from Pharmaceutical Contaminants: Assessment of Environmental Quality Act 1974 and Its Regulations

conservation measures against damage that may cause by the discharge and dumping of EHS and waste.

\section{Responsibilities of Stakeholders}

First responsibility of stakeholder is to identify the existing and emerging threat to source water. Section 37 of EQA, Regulations 4 of EQSR, Regulation 3, 11 and 12 of EQSWR require the information and notification to be provided to the authority in regard to any effluent discharged including up-to-date inventory of scheduled waste.

Further, Regulations 5, 6, 8, 9, 10, and 13 of EQSWR spell out the responsibility of waste generator to provide detail procedures of treatment, recovery of products and the residuals from the recovery, storage, labelling, and transported outside waste generator of scheduled waste.

Next responsibility is to develop and implement methods for source water protection and preservation. The methods to be developed might include policies, guidelines, practices, processes, programmes, standards, and measures for protection and preservation of source water from EHS and any pollutant that might be detrimental to public health. For instance, Regulation 15 of the EQSWR states that every waste generator shall conduct training for his employees in terms of management of scheduled waste including identification, handling, labelling, storage, transportation, spillage, and discharge of scheduled waste.

\section{Best Management Practice}

Best Management Practice (BMP) addressed under Malaysian legislation is relating to the issue of hazardous substances wastes. BMP is defined under Regulation 1 of EQIER as "practical, structural or non-structural methods for the purpose of preventing or reducing the discharge of industrial effluent or mixed effluent containing contaminants". However, the definition was left for various interpretations since there is no specific practice could be considered as BMP. In Malaysia, the provision only applies to the discharge of industrial and mixed effluent, and excluded all other effluent such as domestic and household effluent.

For example, Regulation 14 of EQIER mentioned that BMP should be adopted for industrial effluent or mixed effluent if discharging certain types of contaminant is listed under Ninth Schedule of the regulations. The parameter list in the Ninth Schedule mentions the BMP for discharging endocrine disruptors (EDCs), which could include the synthetic EDCs comprising pharmaceuticals and personal care products (Aris, Shamsuddin, \& Praveena, 2014; Wee \& Aris, 2017).

Basically, BMP is considered as 'something extra' from the regulatory requirement. For example, the protection of water environment from hazardous substances could be the vital part of BMP. This is based on its role in preventing 
PLANNING MALAYSIA

Journal of the Malaysia Institute of Planners (2019)

and protecting hazardous contaminants from entering water environment, and not solely focusing on specific contaminant as discussed in the first part sub-category of BMP.

As one practice of BMP, Malaysian Department of Environment (DOE) has introduced a scheme on Environmentally Hazardous Substances Notification and Registration (EHSNR) whereby manufacturers and importers of EHS are required to submit EHS notification to DOE when the substances are manufactured or imported above certain amount. With this scheme, DOE will have the necessary information on EHS, which enable them to work with other agencies to identify the EHS and prevent this EHS from polluting the environment.

DOE, in 1999, has also published the Guidelines on Handling of Clinical Waste in Malaysia by DOE in 2009. Under the guidelines, consideration is given to generation and minimisation, source separation and segregation, identification and labelling, handling and storage, safe transportation, treatment, and disposal of residues. Since the definition of clinical waste has included pharmaceutical products, therefore, this guideline could be complementary to EQSWR since it detailed out the procedure and the steps to be taken for managing the clinical waste in order to avoid risk to human health and the environment.

\section{Provision Related to Monitoring of Source Water}

\section{Notification and Information from Stakeholder}

Section 37 of EQA makes it necessary for the stakeholder to furnish information with regard to the EHS and the use of EHS and any environmental risk that may result from the use of those materials.

Regulation 4 of EQSR, and Regulations 12 and 13 of EQSWR require the notification and information to be given to the authority regarding the discharge or release of effluent into any inland waters or Malaysia waters. The notification shall be in accordance with First Schedule of EQSR and Sixth Schedule of EQSWR, whereby it shall contain, among others, premises' information, information on sewage treatment, type of waste, waste packaging, quantity, and type of operation. Furthermore, EQSR also touches on the type of contaminants and acceptable parameter of discharge of such contaminants in its Second Schedule.

\section{Environmental Audit}

Environmental audit is a post evaluation approach undertaken after the development of a project to ensure regulations compliance (Yusoff, 2013). Unlike surveillance, specific requirements need to be fulfilled under environmental audit. Section 33A of EQA requires owner or occupier of vehicle, ship, and 
Adillah Othman \& Mariani Ariffin

Source Water Protection from Pharmaceutical Contaminants: Assessment of Environmental Quality Act 1974 and Its Regulations

premise to carry out environmental audit in the manner prescribed by regulations made under the EQA and to submit the report to the authority.

Several environmental quality regulations, such as EQIER, EQSR and EQSWR, have also laid down the acceptable condition of the contaminant to be discharged into source water. Without an environmental audit, the authority could not monitor the compliance to the regulations.

\section{Provision Related to Surveillance of Source Water}

\section{Surveillance Agencies}

Surveillance agencies refer to independent agencies that will conduct surveillance on source water quality. The agencies shall include government ministries and state authorities.

Section 33A (1) of EQA requires the owner or occupier of vehicle, ship, or premises to submit environmental audit report to the authority. Section 33A (2) and (3) further state that the owner or occupier shall appoint qualified personnel who are registered with the authority to carry out the environmental audit.

\section{DISCUSSION}

Based on the analysis, this study found that there are protections in the existing Malaysian legislation for pharmaceutical contaminant in source water. However, there are still gaps especially with regard to pharmaceutical contaminations. Pharmaceutical contaminants have been regulated under various categories such as scheduled waste, EHS, and industrial effluent. From all EQA and its regulations, only four (4) addressed the issue of pharmaceutical residue in their provisions, namely EQA, EQSWR, EQSR, and EQIER.

Only a few has specifically mentioned the types of contaminant that enter the water environment such as EQIER and EQSWR. Other legislation adopted a more general term such as EHS, 'poisonous', and 'noxious' contaminant, which the study has to interpret whether the pharmaceutical contaminants come within the ambit of what the legislation intended to protect. As mentioned in the finding that EHS is among the substance which Malaysian legislation looked into, this could be a good protection to source water since previous literature has recognised pharmaceutical contaminant as one type of EHS component (Milutinoviv \& Trumbulovic, 2014; Motiekaityte \& Venckus, 2016).

While many literatures have reported various pathway of pharmaceutical residue (Al-Odaini et al., 2011; Al-Odaini et al., 2016; Boleda et al., 2011; Kookana et al., 2014) and its released into the environment without any treatment (Lundborg \& Tamhankar, 2017), Malaysian legislation still do not classify pharmaceutical residue as one of the parameters that should be treated in wastewater treatment plant. The worst scenario is, there are currently more than 
200 industries involving pharmaceutical products such as manufacturing, distributing, and consuming (Drug Control Authority, 2016). Lundborg and Tamhankar (2017) further suggested that wastewater treatment plant should be upgraded in order to treat pharmaceutical residue before the residual water being discharged into river or source water.

Effluent discharge is considered as the major source of emission which might contain pharmaceutical contaminants either in its natural form or its metabolites (Rajbongshi, Shah, \& Sajib, 2016). Although the EQIER have specified a certain parameter for the discharge of industrial effluent or mixed effluent, nothing in this legislation refers to pharmaceutical contaminant or as one of the parameters to be considered before discharge. But EQIER lists the catchment areas of water supply intake for the purpose of human consumption (including drinking water) under its Sixth Schedule where the effluent parameter discharge are specified. Thus, EQIER could help in preventing pharmaceutical contaminants in drinking water if pharmaceutical residue is included under the list of the parameter. Further, the category of 'other industries' in Schedule Seventh of Regulation 12 of EQIER is vague since the definition of the 'other industries' is unclear whether it includes pharmaceutical industries.

Apart from the categorisation of pharmaceutical waste as scheduled waste under EQSWR, none of the legislation mentioned the approach to handle pharmaceutical waste from other sources such as household waste and non-point source (Alshakka et al., 2016; Gaw, Thomas, \& Hutchinson, 2014; Gorman, 2010; Lundborg \& Tamhankar, 2017; Rajbongshi et al., 2016). This could lead to the unlawful disposal of such contaminants into the environment such as via trash and flushing down the toilet (Vatovec, Van Wagoner, \& Evans, 2017). The scope of scheduled waste under existing legislation should be expanded in order to cover various types of pharmaceutical contaminants and its sources.

The result showed that the legislation listed has fulfilled both legal capacity and monetary capability. It gives full power to the authority to protect the environment from pollution. Addiionally, previous literature also mentioned that among the key components to protect source water is the capability to make and access of funding, and when the fund is able to meet the expenses of water management (Al Ibrahim \& Patrick, 2017).

In Malaysian legislation, there are several provisions referring to monitoring such as information sharing, notification of discharge of contaminant, and environmental audit. Except Regulation 12 of EQSWR, which states that scheduled waste should include pharmaceutical, other legislation do not mention specifically about pharmaceutical contaminant.

It has been reported that a lot of pharmaceutical contaminants are polluting the environment, yet there is lack of documentation, making this type of pollution difficult to manage (Lundborg \& Tamhankar, 2017; Milutinoviv \& Trumbulovic, 2014). Monitoring could be considered as one of the important 
Adillah Othman \& Mariani Ariffin

Source Water Protection from Pharmaceutical Contaminants: Assessment of Environmental Quality Act 1974 and Its Regulations

methods since the information acquired could be used to administer the type of waste from risking the environment and new innovation of technologies could be proposed in order to protect source water from pharmaceutical contaminant (Lundborg \& Tamhankar, 2017). It would alert the authority to develop inventory management, later allow the control to the amount of hazardous pharmaceutical waste generated (Priya, 2017).

In addition, routine surveillance can guide the development and implementation of appropriate contextual interventions (Lundborg \& Tamhankar, 2017). EQA does mention the independent bodies to carry out the surveillance and audit, yet their responsibilities are not detailed out.

\section{CONCLUSION}

The loopholes in Malaysian legislation basically relating to source water management, including the inclusion of pharmaceutical contaminant as the part of "waste" and "parameter" that legislation should be looked into. WHO (2011) has urged for the existing policies to be improved on the management of pharmaceutical waste.

The finding of this study could give better information on the relevant methods, in which Malaysian legislation should improve in order to protect source water from pharmaceutical contaminants since public health is likely to be negatively affected if this problem remained unattended. Advancement of technical innovations is very crucial. Nevertheless, the improvement of technology is useless if pharmaceutical contaminants were not included in the legislation parameter. Apart from that, many countries such as US, Europe, and Canada have proven that among the best and economical way to cope with this issue of pharmaceutical waste is via "take-back" programme.

In conclusion, source water protection from pharmaceutical contaminants could not be done by single action. The protection involves multiple and various actions to realise the aim of having pharmaceutical-safe water supplies.

\section{ACKNOWLEDGEMENT}

This work was supported by the Ministry of Higher Education, Malaysia (KPT) under Trans-Disciplinary Research Grant Scheme (TRGS) [TRGS/2016/5535712]. We wish to thank all our colleagues who have provided professional support and constructive criticism in order to complete this paper. 


\section{REFERENCES}

Al-Odaini, N. A., Zakaria, M. P., Yaziz, M. I., Surif, S., \& Abdulghani, M. (2011). The occurrence of human pharmaceuticals in wastewater effluents and surface water of Langat River and its tributaries, Malaysia. International Journal of Environmental Analytical Chemistry, 7319(February 2015), 1-20.

Al-Odaini, N., Zakaria, M. P., Yaziz, M. I., \& Surif, S. (2016). Detecting human pharmaceutical pollutants in Malaysian aquatic environment: A new challenge for water quality management. In M. P. Zakaria, M. I. Mohamed, \& S. Kasmin (Eds.), Contemporary environmental quality management in Malaysia and selected countries. Serdang: Universiti Putra Malaysia Press.

Al Ibrahim, A., \& Patrick, R. J. (2017). Source water protection planning and management in metropolitan Canada: A preliminary assessment. Water, 9(7), 497.

Alshakka, M., Ibrahim, M. I. M., Hassali, M. A., Palaian, S., \& Aljadhey, H. (2016). Hazards of pharmaceuticals in water as new area in Eco-Pharmacovigilance Research. Journal of Pharmacy Practice and Community Medicine, 2(1), 3-8.

Aris, A. Z., Shamsuddin, A. S., \& Praveena, S. M. (2014). Occurrence of $17 \alpha-$ ethynylestradiol (EE2) in the environment and effect on exposed biota: A review. Environment International, 69, 104-119.

Boleda, M. R., Galceran, M. T., \& Ventura, F. (2011). Behavior of pharmaceuticals and drugs of abuse in a drinking water treatment plant (DWTP) using combined conventional and ultrafiltration and reverse osmosis (UF/RO) treatments. Environmental Pollution, 159(6), 1584-1591.

Canadian Council of Ministers of the Environment. (2004). From source to tap: Guidance on the multi-barrier approach to safe drinking water. Winnipeg: Author.

Drug Control Authority. (2016). Pharmaceutical industry.

Gaw, S., Thomas, K. V., \& Hutchinson, T. H. (2014). Sources, impacts and trends of pharmaceuticals in the marine and coastal environment. Philosophical Transactions of the Royal Society B, 369, 20130572.

Gorman, J. A. (2010). Drugs in our water: A legal proposal for responsible nationwide pharmaceutical consumption. Florida State University of Land Use \& Environmental Law, 26(1), 147-178.

Jelic, A., Gros, M., Ginebreda, A., Cespedes-Sanchez, R., Ventura, F., Petrovic, M., \& Barcelo, D. (2011). Occurrence, partition and removal of pharmaceuticals in sewage water and sludge during wastewater treatment. Water Research, 45, 1165-1176.

Kookana, R. S., Williams, M., Boxall, A. B. A., Larsson, D. G. J., Gaw, S., Choi, K., ...\& Carriquiriborde, P. (2014). Potential ecological footprints of active pharmaceutical ingredients: An examination of risk factors in low-, middle- and high-income countries. Philosophical Transactions of the Royal Society B: Biological Sciences, 369(1656), 20130586.

Lundborg, C. S., \& Tamhankar, A. (2017). Antibiotic residues in the environment of South East Asia. The BMJ, 358(Suppl. 1), 42-45.

Milutinoviv, V., \& Trumbulovic, L. (2014). Higher education in function of sustainable development of tourism in Serbia and Western Balkans: Students' papers proceeding. (L. Trumbulovic; \& N. Milutivonic, Eds.). Business and Technical 
Adillah Othman \& Mariani Ariffin

Source Water Protection from Pharmaceutical Contaminants: Assessment of Environmental Quality Act 1974 and Its Regulations

College of Vocational Studies.

Motiekaityte, V., \& Venckus, Z. (2016). Legal regulation of pharmaceutical waste management in Lithuania. Professional Studies: Theory and Practice, 2(17), 2633.

Plummer, R., Velaniskis, J., de Grosbois, D., Kreutzwiser, R., \& Rob, de L. (2010). The development of new environmental policies and processes in response to a crisis: The case of the multiple barrier approach for safe drinking water. Environmental Science and Policy, 13(6), 535-548.

Priya, P. (2017). Management of pharmaceutical waste. Journal of Drug Discovery and Therapeutics, 5(2), 1-8.

Rajbongshi, S., Shah, Y. D., \& Sajib, A. U. (2016). Pharmaceutical waste management: A review. European Journal of Biomedical and Pharmaceutical Sciences, 3(12), 192-206.

The Council of the European Union. (1998). Council Directive 98/83/EC of 3 November 1998 on the quality of water intended for human consumption. Official Journal of the European Communities, L330, 32-54.

Vatovec, C., Van Wagoner, E., \& Evans, C. (2017). Investigating sources of pharmaceutical pollution: Survey of over-the-counter and prescription medication purchasing, use, and disposal practices among university students. Journal of Environmental Management, 198(Part 1), 348-352.

Wee, S. Y., \& Aris, A. Z. (2017). Endocrine disrupting compounds in drinking water supply system and human health risk implication. Environment International, 106(April), 207-233.

World Health Organization. (2004). Water Safety Plans: Managing drinking-water quality from catchment to consumer. https://doi.org/10.4324/9781315693606

World Health Organization. (2001). Guidelines for drinking-water quality. Geneva: Author.

Yusoff, H. N. (2013). Understanding environmental audit in the public sector: Malaysian perspective. Jurnal Teknologi, 62(1), 25-30

Received: $12^{\text {th }}$ January 2019. Accepted: $2^{\text {nd }}$ August 2019 